Dr Gordana Radivojevic, dipl. inž.
Institut „Mihajlo Pupin“",
Beograd
HEURISTICKI ALGORITAM ZA PROJEKTOVANJE RUTA VOZILA U TRANSPORTNOM SISTEMU „NAZOVI VOŽNJU“

UDC: $519.857: 656.022 .1 / .5$

Rezime:

Transportni sistem „Nazovi vožnju“ (Dial-a-Ride) oblik je prevoza u kojem prevozilac poseduje vozni park $i$ realizuje prevoz na relacijama i u vreme kako to zahtevaju korisnici. Osnovni problem organizatora pevoza je definisanje ruta i reda vožnje saobracajnih sredstava, tako da se realizuje skup zahteva za prevoz. U radu je opisan heuristicki algoritam za projektovanje ruta i redova vožnje saobracajnih sredstava za staticki slucaj transportnog sistema „Nazovi vožnju“. Razvijeni heuristicki algoritam ima mogucnost primene u konkretnim uslovima.

Kljucne reci: heuristicki algoritam, projektovanje ruta vozila, dinamicko programiranje.

\title{
HEURISTIC ALGORITHM FOR STATIC DIAL-A-RIDE PROBLEM
}

\section{Summary:}

Dial-a-Ride system is a way of transport in which a transporter owns a fleet and realizes transport when and where customers ask for it. Different versions of this type of transportation are present in every day practice. The main problem here is route design and scheduling to realize the set of transport requests. In this paper it is described a heuristic algorithm for route design and scheduling for the static Dial-a-Ride problem. The developed algorithm can be applied in real situations.

Key words: heuristic algorithm, vehicle route design, dynamic programming.

\section{Uvod}

Razlicite varijante ovog transportnog sistema „Nazovi vožnju“ (Diala-Ride) postoje u svakodnevnoj praksi: prevoz starih i bolesnih lica, prevoz u oblastima sa malom gustinom naseljenosti, gde ne postoji javni gradski prevoz, razliciti oblici prevoza u gradskim komunat nim službama, prevoz zaposle nih u velikim poslovnim sistemima, i dr. Pri rešavanju proble ma projektovanja ruta i redova vožnje mogu se definisati staticki i dinamickii slucaj. Sta ticki slucaj podrazumeva da su skup zahteva za prevozom i podaci o saobracajnim sredstvima unapred poznati. Tada se rute red vožnje projektuju za neki buduci period sa poznatim parametrima transportnog procesa. Dinamicki slucaj podrazumeva rešavanje problema projektovanja ruta i reda vožnje saobracajnih sredstava u realnom vremenu.

Postupak projektovanja ruta i reda vožnje predstavlja kombinatorni zadatak, jer iz skupa razlicitih kombinacija opsluge zahteva treba izabrati onu kombinaciju koja u najvecoj meri odgovara postavlje nim cilje vima [6, 5]. Prevozilac naj cešce želi da svojim prevoznim kapacite- 
tima realizuje što veci broj zahteva, odnosno, da ostvari što veci prihod. Projektovanje ruta i reda vožnje saobracajnih sredstava podrazumeva rasporedivanje skupa zahteva za prevoz na skup ras položivih vozila iz voznog parka, i definisanje tacnih vremenskih momenata pocetka i završetka svakog zahteva.

Proble mi projektovanja ruta i reda vožnje mogu se rešavati primenom optimizacionih tehnika ili heuristic kih algoritama. Optimizacione tehnike, koje se naj cešce koriste, je su dinamic ko programiranje i metoda grananja i ogranicavanja. Primena optimizacionih me toda omogucava dobijanje najboljeg rešenja, sa aspekta de finisanih kriterijuma. U praksi je primena optimizacionih metoda ogranicena dimenzijama proble ma koji se rešava. Sa njihovim porastom (broja cvorova transportne mreže i broja zahteva za prevoz), znatno se povecava vreme rada racunara, pa primena ovih metoda nije uvek moguca. Zato se veliki broj problema u obla sti projektovanja ruta i redova vožnje rešava primenom razlicitih he uristic kih algoritama [4, 3]. Heuristic ki at goritmi mogu se primeniti za rešavanje proble ma velikih dimenzija i veoma brzo se izvršavaju. Dobijena rešenja nisu optimalna, ali su veoma bliska optimalnim. U praksi ne postoji pravilo o primeni ovih me toda. Primena he uristic kih algoritama ili optimizacionih metoda zavisi od konkretnog proble ma koji se rešava.

Cilj ovoga rada je rešavanje problema projektovanja ruta i redova vožnje za staticki slucaj sistema Dial-a-Ride. U radu je prikazan heuristicki algoritam za projektovanje ruta i reda vožnje, koji se u jednom koraku zasniva na primeni me tode dina mic kog programiranja.

\section{Opis problema}

Transportni sistem „Nazovi vožnju“ (Dial-a-ride) je oblik prevoza u kome prevozilac poseduje vozni park, kojim obavlja prevoz putnika na odredenom podrucju - transportnoj mreži. Prevoz se realizuje na relacijama i u vreme kako to zahtevaju putnici. Osnovni cilj prevozioca je opsluživanje skupa zahteva za prevozom u odredenom periodu. Projektovanje ruta i redova vožnje podrazumeva rasporedivanje vozila iz voznog parka na skup zahteva za prevozom.

Razlicite varijante transportnog sistema „Nazovi vožnju“ moguce je kla sifikovati prema osnovnim karakteristikama transportnog sistema [1]: broj vozila u voznom parku, kapacitet vozila, struktura voznog parka, broj depoa na transportnoj mreži, vremenske karakteristike zahteva za prevoz, kriterijumi projektovanja ruta, ogranicenja u sistemu, sta ticka i dinamic ka varijanta proble ma i dr. Nacin rešavanja proble ma projektovanja ruta i reda vožnje zavisi od navedenih karakteristika sistema.

U ovom radu posmatra se staticki slucaj transportnog sistema „Nazovi vožnju“. Prevozilac - organizator prevoza svojim voznim parkom obavlja prevoz na teritoriji grada. Zahtevi za prevoz evidentiraju se telefonom u dispecerskom centru prevozioca, a prikupljaju se dan ranije. Na kraju radnog dana projektuju se rute i red vožnje vozila za sle deci dan. Pri tome se uzimaju u obzir svi evidentirani zahtevi za prevoz i sva raspoloživa vozila iz voznog parka.

Zahtevi za prevoz realizuju se na odredenoj transportnoj mreži. Transportna mreža je gradsko podrucje, koje se sastoji od 
skupa cvorova - gradskih raskrsnica, i skupa ulica, koje povezuju te cvorove. Osnovne karakteristike transportne mreže su:

M - broj cvorova na mreži,

$\mathrm{X}_{\mathrm{p}}, \mathrm{Y}_{\mathrm{p}}$ - koordinate cvora $\mathrm{p}$ na mreži,

$\mathrm{D}_{\mathrm{pq}}$ - rastoja nje izmedu cvorova $\mathrm{p}$ i $\mathrm{q}$,

$\mathrm{TT}_{\mathrm{pq}}$ - vreme putovanja izmedu cvorova $\mathrm{p}$ i q.

Prevozilac poseduje homogen vozni park, koji se sastoji od N vozila. Kapacitet vozila je je dan putnik. Na transportnoj mreži postoji je dan depo, lociran u cvoru D. Dozvolje no radno vreme vozila je R i projektovane rute vozila moraju zadovolja vati ogranicenje radnog vremena. Vozila su na pocetku radnog dana u depou, odatle odlaze na realizaciju svojih ruta, a na kraju rada ponovo se vracaju u de po. Jedno vozilo u toku dana realizuje više zahteva za prevoz, iz depoa odlazi do mesta pocetka prvog zahteva, opslužuje ga na zadatoj relaciji, zatim odlazi do mesta pocetka sle deceg zahteva, opslužuje ga, itd. Posle opsluge poslednjeg zahteva na svojoj ruti vozilo se vraca u depo.

Pod zahtevom za prevoz podrazumeva se prevoz jednog putnika na odredenoj relaciji i u odredeno vreme. Korisnik prija vljuje prevoziocu zahtev za prevoz (i) i nje gove osnovne karakteristike:

$\mathrm{i}^{+}$- cvor pocetka op sluge zahteva (i),

i- cvor završetka opsluge zahteva (i), $\mathrm{DPT}_{\mathrm{i}}$ - vreme pocetka opsluge zahteva (i).

Zahtev za prevoz opisan je že lje nim vremenom pocetka opsluge. Vreme $\mathrm{DPT}_{\mathrm{i}}$ predstavlja vremenski momenat kada mora poceti prevoz putnika na željenoj relaciji. Na osnovu najkraceg vremena putovanja na mreži, za svaki zahtev (i) izracunava se vreme trajanja opsluge $D_{T T}, t j$. vreme direktnog putovanja na relaciji od $\mathrm{i}^{+}$do i. Vremenski moment završetka opsluge je $\mathrm{DDT}_{\mathrm{i}}$, a odreduje se kao:

$$
\mathrm{DDT}_{\mathrm{i}}=\mathrm{DPT}_{\mathrm{i}}+\mathrm{DTT}_{\mathrm{i}}
$$

Vremenski momenti pocetka i za vršetka svakog zahteva ne mogu se menjati u odnosu na zadate vrednosti. Postupak projektovanja ruta i reda vožnje treba da obezbedi raspodelu skupa zahteva na skup raspoloživih vozila i za svako vozilo definisanje redosleda opsluge dodeljenih zahteva.

U ovom radu odredeni su kriterijumi projektovanja ruta i reda vožnje [10]: vreme trajanja praznih vožnji, vreme cekanja vozila na pocetak realizacije sle deceg zahteva na ruti.

Pod praznom vožnjom podrazumeva se vreme potrebno da vozilo dode od mesta završetka prethodnog zahteva do mesta pocetka sle deceg zahteva na ruti. Stajanje - cekanje vozila je period kada vozilo stoji u mestu pocetka zahteva, cekajuci mome nat pocetka nje gove realizacije.

Pove zivanjem zahte va (i) i (j) u rutu jednog vozila ostvaruju se uš tede u ukupnom predenom putu i u predenom putu bez putnika (prazne vožnje). Da bi se zahtevi mogli realizovati istim vozilom potrebno je da bude ispunjen uslov:

$\mathrm{DPT}_{\mathrm{j}} \geq \mathrm{DDT}_{\mathrm{i}}+\mathrm{TT}_{\mathrm{i}-\mathrm{j}}$

gde je $\mathrm{TT}_{\mathrm{i} \mathrm{j}^{+}}$vreme putovanja od za vršetka zahteva (i) do pocetka zahteva (j). Zahtevi (i) i (j) mogu se spojiti u jednu rutu ako je vremenski moguce da vozilo posle realizacije zahteva (i) dode od cvora $\mathrm{i}^{-}$do cvora $j^{+}$pre za datog vremena pocetka realizacije zahteva (j) - DPT . Spajanjem zahteva u jednu rutu ostvaruju se uštede u predenom putu, jer se vozilo ne vraca u depo posle realizacije svakog zahteva. 


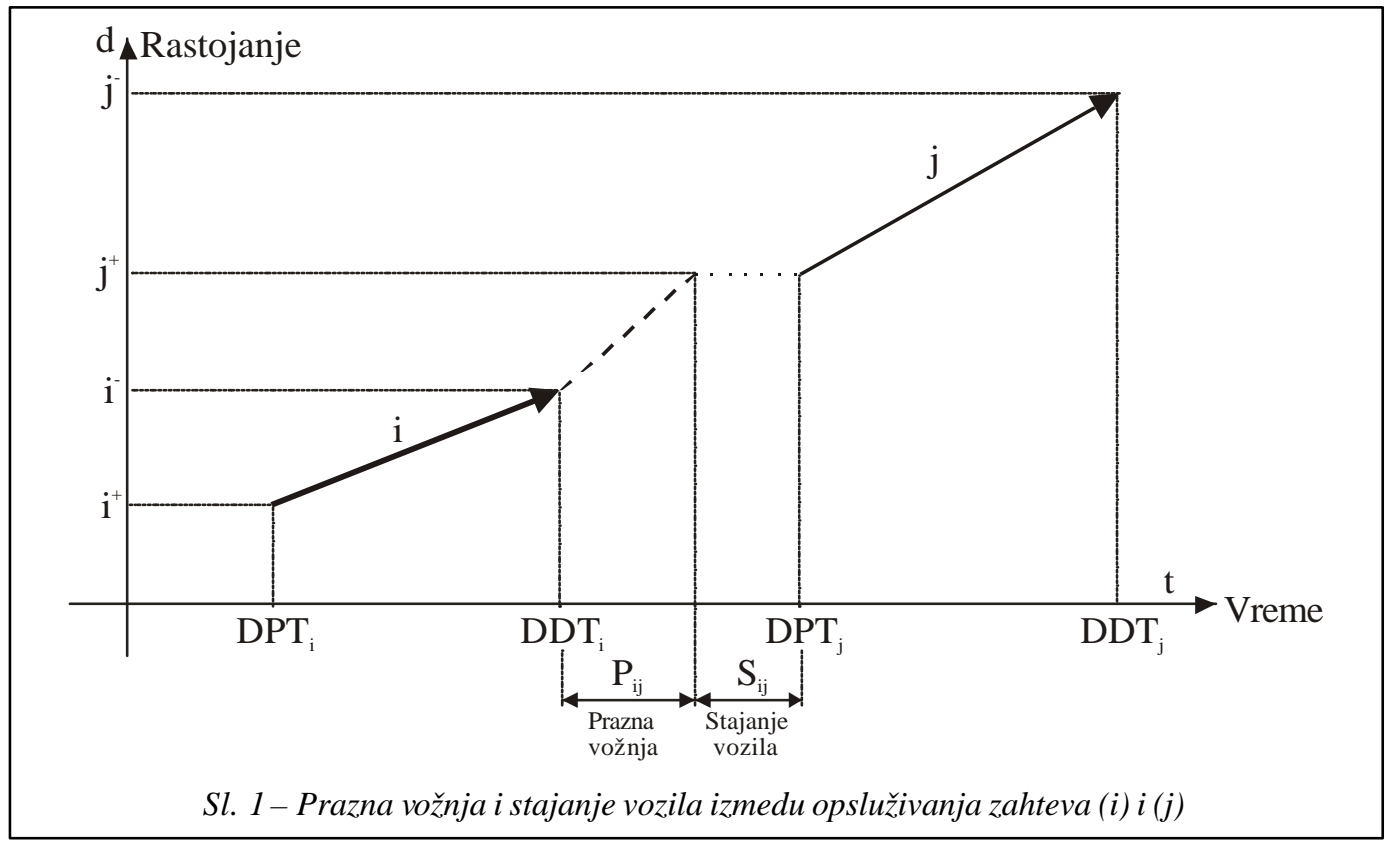

Kada se istim vozilom realizuje više zahteva korisnika za prevozom, dolazi do praznih vožnji i stajanja - cekanja vozila na pocetak realizacije sle deceg zahteva na ruti. Na slici 1 prikazani su prazna vožnja i staja nje vozila izmedu zahteva (i) i (j).

Funkcija cilja pri projektovanju ruta i reda vožnje vozila je ukupno vreme trajanja praznih vožnji i staja nja vozila. Prema slici 1, vreme trajanja prazne vožnje $\left(\mathrm{P}_{\mathrm{ij}}\right)$ pri realizaciji zahteva (i) $\mathrm{i}(\mathrm{j}) \mathrm{je}$ :

$\mathrm{P}_{\mathrm{ij}}=\mathrm{TT}_{\mathrm{i}-\mathrm{j}+}$

a vreme stajanja $S_{\mathrm{ij}}$ je:

$\mathrm{S}_{\mathrm{ij}}=\mathrm{DPT}_{\mathrm{j}}-\mathrm{DDT}_{\mathrm{i}}-\mathrm{TT}_{\mathrm{ij} \mathrm{j}^{+}}$

Ukupno vreme trajanja prazne vožnje i sta janja vozila pri realizaciji zahteva (i) $i(j) j e:$

$\mathrm{P}_{\mathrm{ij}}+\mathrm{S}_{\mathrm{ij}}=\mathrm{DPT}_{\mathrm{j}}-\mathrm{DDT}_{\mathrm{i}}$
U ovom radu se, pri projektovanju ruta i reda vožnje, teži minimiziranju ukupnog vremena trajanja praznih vožnji i stajanja vozila, a funkcija cilja je:

$$
\begin{aligned}
& F=\sum_{i=1}^{Z} \sum_{j=1}^{Z}\left(D^{2} T_{j}-D D T\right) \\
& \mathrm{i} \neq \mathrm{j} \\
& \mathrm{DPT}_{\mathrm{j}} \geq \mathrm{DDT}_{\mathrm{i}}+\mathrm{TT}_{\mathrm{ij}}
\end{aligned}
$$

\section{Heuristicki algoritam}

Algoritam za rešavanje proble ma projektovanja ruta zasniva se na primeni optimizacione metode dinamickog programiranja. Algoritam se sastoji od sledecih koraka [10]:

- korak 1: priprema podataka iz skupa ula znih ve licina,

- korak 2: primena dinamic kog programiranja i ge nerisanje skupa ruta, 
- korak 3: analiza karakteristika dobije nih ruta vozila.

Korak 1: priprema podataka iz skupa ulaznih velicina

Ulazne velicine obuhvataju podatke o transportnoj mreži, podatke o voznom parku i podatke o zahtevima za prevoz. Pre primene postupka projektovanja ruta i reda vožnje neophodno je ažurirati podatke o svim raspoloživim vozilima i o skupu evidentiranih zahteva za prevozom.

Korak 2: primena dinamickog programiranja i generisanje skupa ruta

Ruta vozila se projektuje radi primene dina mic kog programiranja. Pri dodeljivanju zahteva vozilu vodi se racuna o uslovima spajanja dva zahteva u jednu rutu i o ogranicenju radnog vremena vozila. Od skupa od Z evidentiranih zahteva za prevoz formira se mreža za primenu dinamickog programiranja. Primer ovako definisane mreže prikazan je na slici 2.

Osnovne karakteristike mreže za primenu dinamic kog programiranja su:

- cvorovi mreže su zahtevi za prevoz, koje treba oba viti;

- cvorovi na mreži grupisani su u etape, gde svaka etapa predstavlja redni broj zahteva na ruti jednog vozila;

- mreža se sastoji od $(Z+1)$ etape, gde je $\mathrm{Z}$ broj evidentiranih zahteva za prevoz;

- u nultoj etapi nalazi se cvor D, koji predstavlja de po voznog parka, od kojeg se polazi u postupku projektovanja ruta;

- u prvoj i svakoj sle decoj etapi nalaze se svi cvorovi - zahtevi za prevoz.
Grane na mreži povezuju cvorove u dve susedne eta pe. Izme du bilo koja dva cvora (i) i (j), koji pripadaju susednim etapama (z-1) i (z) i zadovolja vaju uslov $\mathrm{i} \neq \mathrm{j}$, uvek postoji grana koja ih spaja. $\mathrm{Na}$ mreži mogu postojati „prave grane“ i „veštacke grane“. „Prava grana“ spaja cvor (i) u etapi (z-1) i cvor (j) u etapi (z), ako je moguce istim vozilom realizovati zahtev (i), pa zahtev (j), tj. ako je is punjen uslov:

$\mathrm{DPT}_{\mathrm{j}} \geq \mathrm{DDT}_{\mathrm{i}}+\mathrm{TT}_{\mathrm{ij}+}$

Dužina „prave grane“ jednaka je zbiru vremena trajanja prazne vožnje izmedu zahteva (i) i (j), vremena stajanja vozila do pocetka zahteva (j) i vremena trajanja realizacije zahteva (j). Dužina „prave grane“ je $R_{\mathrm{ij}}$ i odreduje se kao:

$\mathrm{R}_{\mathrm{ij}}=\mathrm{DPT}_{\mathrm{j}}-\mathrm{DDT}_{\mathrm{i}}+\mathrm{DTT}_{\mathrm{j}}$

Ako zahtevi (i) i (j) ne zadovoljavaju uslov (7), tj. ako se zahtev (j) ne može realizovati istim vozilom posle zahte va (i), ta da izmedu cvora (i) u etapi (z-1) i cvora (j) u eta pi (z) postoji „veštacka grana“. Postojanje ,veštacke grane“ izmedu cvorova (i) i (j), znaci da je (i) poslednji zahtev na ruti jednog vozila, a da se za realizaciju zahteva (j) uvodi novo vozilo iz depoa. Dužina „veštacke grane“ predstavlja zbir vremena trajanja vožnje od depoa do mesta pocetka zahteva (j) i vremena trajanja realizacije zahteva (j). Dužina „veštacke grane" izmedu cvorova (i) i (j) je $\mathrm{R}_{\mathrm{ij}}$ i izracunava se kao:

$\mathrm{R}_{\mathrm{ij}}=\mathrm{Q}+\mathrm{TT}_{\mathrm{Dj}+}+\mathrm{DTT}_{\mathrm{j}}$ 


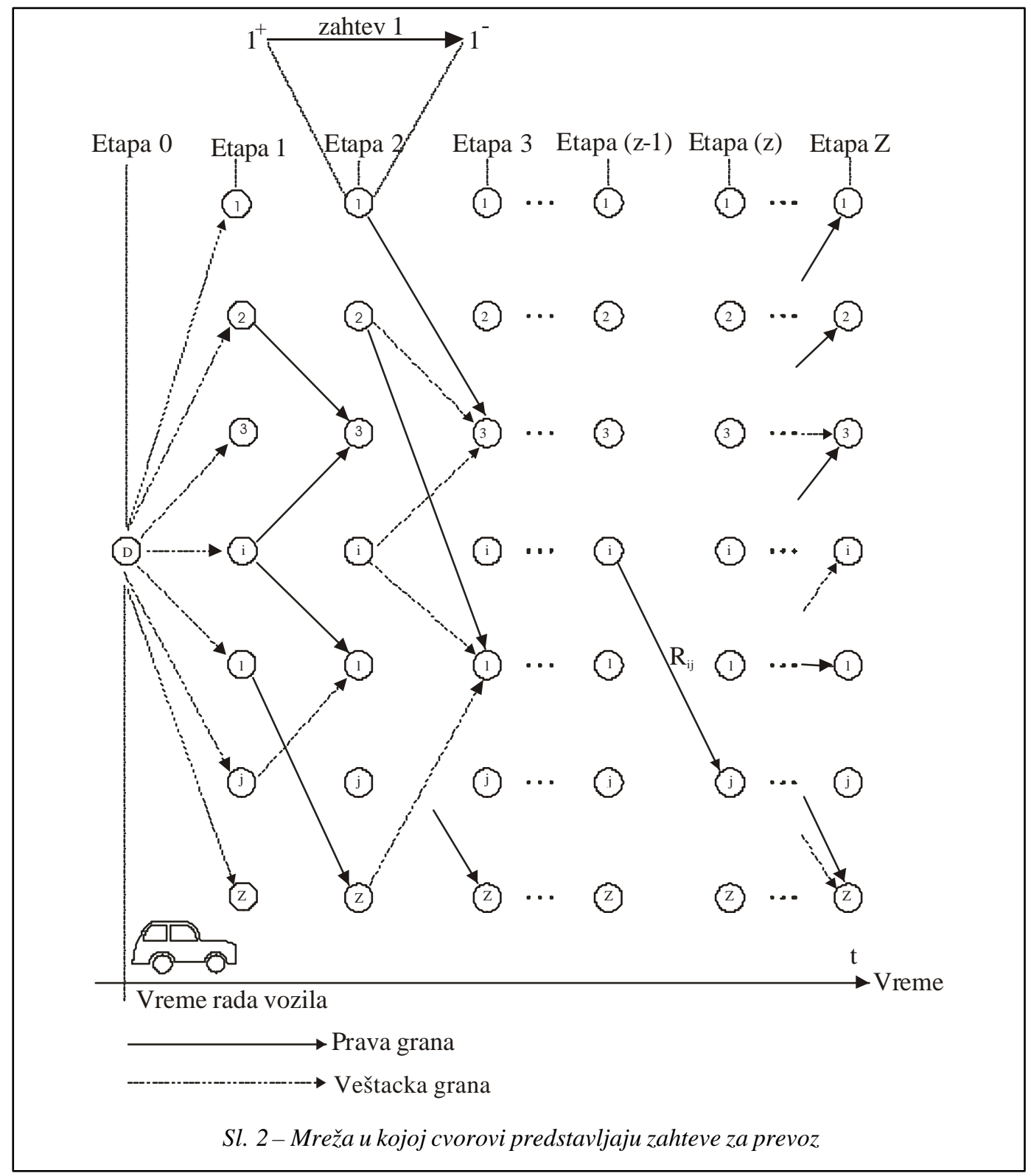

Konstanta Q ima veoma veliku vrednost $(1,000.000)$ i oznacava angažovanje novog vozila iz depoa. Kada u poslednjoj etapi projektovanja ruta na mreži dinamickog programiranja dobije vrednost funkcije cilja, tada cifra na poziciji miliona oznacava broj vozila neophodnih za realizaciju svih zahteva. Grane koje spajaju cvor D u nultoj etapi i sve cvorove u prvoj etapi su ,veštacke grane“, jer se u prvom koraku za svaki zahtev angažuje vozilo iz de poa. Na svakoj sle decoj etapi definisanje grana izmedu bilo koja dva cvora radi se prema uslovu (7). 
Na ovako definisanoj mreži potrebno je pronaci puteve najmanje ukupne dužine, koji prolaze kroz sve cvorove mreže. Relacije dinamickog programiranja su:

$$
\begin{aligned}
& \mathrm{F}_{0}(0)=0 \\
& \mathrm{~F}_{\mathrm{z}}(\mathrm{j})=\min \left\{\mathrm{F}_{\mathrm{z}-1}(\mathrm{i})+\mathrm{R}_{\mathrm{ij}}\right\} \mathrm{z}=1,2, \ldots, \mathrm{Z} \\
& \quad \text { Dopustive grane }(\mathrm{i}, \mathrm{j})
\end{aligned}
$$

gde je:

$\mathrm{z}$ - etapa,

j- cvor u (z)-oj etapi,

i - cvor u (z-1)-oj etapi,

$F_{z}(j)$ - dužina najkraceg puta do cvora $(j)$

u (z)-oj etapi,

$F_{z-1}(i)$ - dužina najkraceg puta do cvora

(i), u (z-1)-oj etapi,

$\mathrm{R}_{\mathrm{ij}}$ - dužina grane izmedu cvora (i) u (z1)-oj etapi i cvora (j) u (z)-toj etapi.

Relacije dinamickog programiranja omogucavaju odredivanje najkraceg puta od pocetnog cvora do nekog cvora u (z)toj eta pi. Pronadeni najkraci put do cvora (j) u (z) -toj etapi može da sadrži prave grane i veštacke grane. Postojanje veštacke grane na najkracem putu ukazuje na angažovanje novog vozila kojim se realizuje zahtev. Pri uklju civanju cvora (j) u najkraci put potrebno je proveriti ogranicenja u pogledu dozvoljenog radnog vremena vozila R. Ako ova ogranicenja nisu zadovoljena, umesto ,prave grane“ uvodi se ,veštacka grana“ do cvora (j), tj. novo vozilo iz depoa za realizaciju zahteva (j). Pri uklju civanju cvora (j) u najkraci put potrebno je proveriti da li je on u nekoj prethodnoj etapi bio ukljucen. Nije dan cvor se ne može dva puta uklju citi u najkraci put. Vrednost funkcije cilja $F_{z}(j)$ predstavlja ukupno vreme trajanja realizacije svih zahteva, zakljucno sa zahtevom (j) na (z)-toj etapi. Postupak dina mic kog programiranja se za vršava kada su svi cvorovi ukljuceni u naj kraci put.

Kao izlazni rezultat dinamickog programiranja dobija se jedna velika ruta za koju je vrednost definisane funkcije cilja minimalna. Na slici 3 prikazan je jedan primer rešenja dobijenog primenom izloženog postupka projektovanja ruta vozila. Dobijeno rešenje predstavlja skup ruta, kojima se realizuje skup od 10 evidentiranih zahteva za prevoz.

Korak 3: analiza karakteristika dobijenih ruta vozila

Primenom dinamickog programiranja dobija se rešenje - jedna velika ruta, koja predstavlja skup pojedinacnih ruta vozila. Na me stima postojanja ,veštackih grana“ velika ruta se deli na de onice. Jedna deonica predstavlja rutu jednog vozila sa skupom dodelje nih zahteva, koje to vozilo realizuje. Rešenje obuhvata skup ruta vozila kojima se realizuju svi evidentirani zahtevi. U ovom koraku predvideno je da dispecer proveri projektovane rute svih vozila i na osnovu svog znanja, is kustva i intuicije unese eventualne korekcije. Korekcije dispecera mogu biti promene termina nekih zahteva za prevoz, koje u znatnoj meri mogu da poboljšaju kvalitet dobije nih rešenja. Posle ovih korekcija ide se ponovo na korak 1 algoritma. Postupak korekcija i projektovanja ruta može da se izraduje iz više iteracija. Na kraju se dobija konacan skup ruta i red vožnje vozila za sve evidentirane zahteve za prevoz. $\mathrm{Za}$ rute vozila definisani su razliciti pokazatelji, koji omogucavaju kompletnu analizu rada voznog parka. 


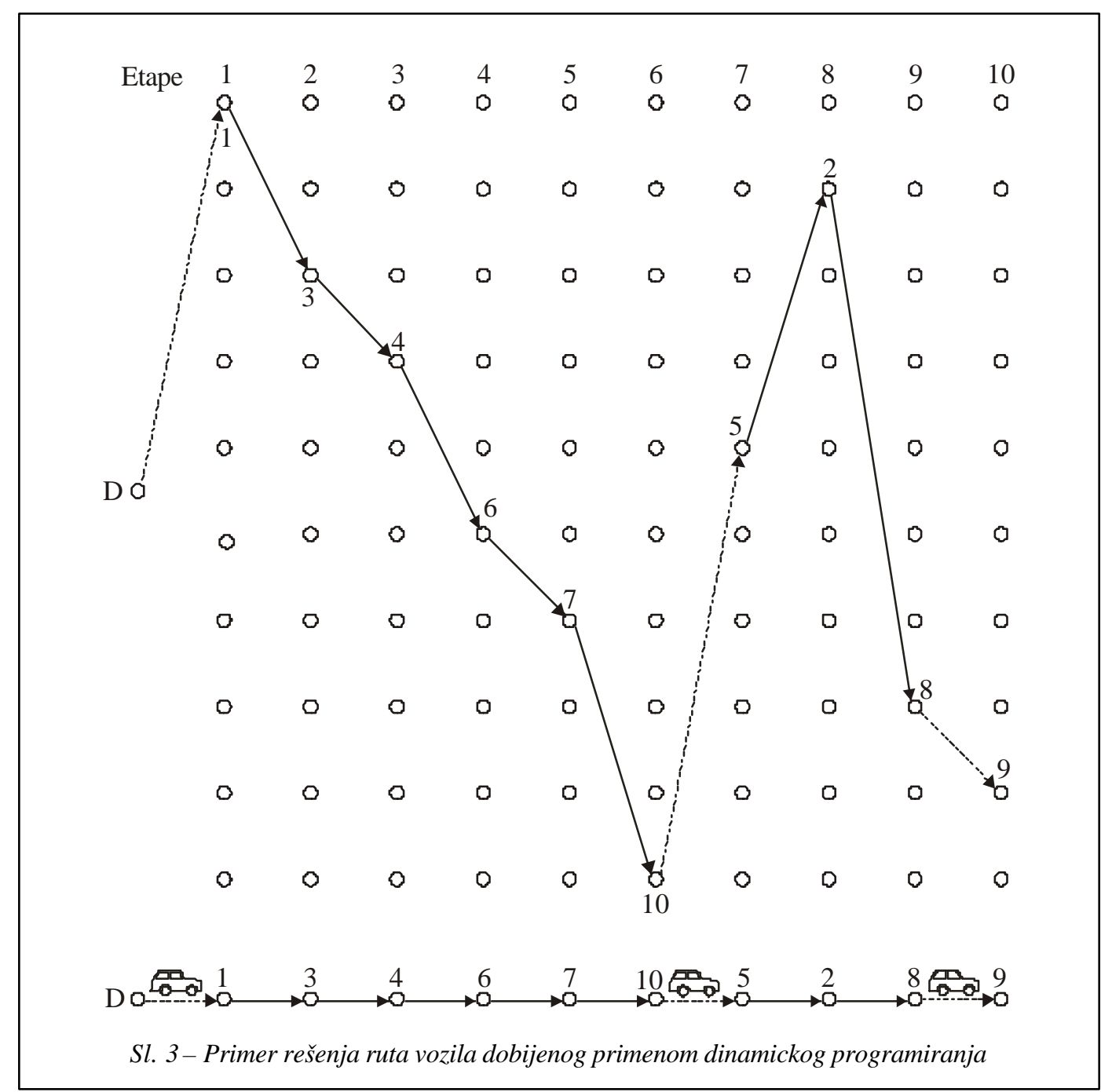

\section{Numericki primeri}

Prema opisanom he uristickom algoritmu razvijen je softverski paket, koji omogucava nje govo testiranje u konkretnim uslovima rada [10]. Transportna mreža je definisana na slucajan nacin $\mathrm{i}$ sastoji se od 13 cvorova. Maksimalno rastojanje na mreži iznosi $16,7 \mathrm{~km}$. Vozni park prevozioca je homogen i sastoji se od 20 vozila. Dozvolje no radno vreme vozila je 8 casova, a prosecna brzina vozila na mreži $40 \mathrm{~km} / \mathrm{h}$. Testiranje je uradeno za razlicite skupove zahteva za prevoz: 80,100 i 120 zahteva u toku dana.

U tabeli 1 prikazan je skup dobijenih ruta vozila za 80 zahteva za prevoz. U tabeli je za svako angažovano vozilo dat skup zahteva, koje vozilo realizuje u toku dana. Ovde su prikazane rute dobijene jednim prolaskom kroz algoritam, bez dodatnih korekcija dis pecera. 
Tabela 1

Projektovane rute vozila

\begin{tabular}{|c|c|}
\hline Vozilo & Zahtevi za prevoz \\
\hline 1 & $\begin{array}{llllllllllllllll}16 & 17 & 23 & 25 & 34 & 35 & 36 & 38 & 39 & 42 & 43 & 45 & 47 & 50 & 51 & 57\end{array}$ \\
\hline 2 & $\begin{array}{llllllllllll}3 & 6 & 8 & 9 & 12 & 13 & 15 & 18 & 24 & 27 & 33 & 37\end{array}$ \\
\hline 3 & $\begin{array}{llllllllll}2 & 1 & 4 & 7 & 11 & 10 & 14 & 22 & 28 & 30\end{array}$ \\
\hline 4 & $\begin{array}{lllllllll}20 & 26 & 40 & 44 & 49 & 52 & 58 & 63 & 66\end{array}$ \\
\hline 5 & 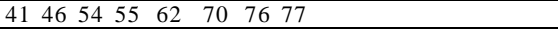 \\
\hline 6 & $\begin{array}{llllll}48 & 56 & 59 & 67 & 74 & 78 \\
\end{array}$ \\
\hline 7 & \begin{tabular}{llllll|}
53 & 60 & 61 & 68 & 71 & 79 \\
\end{tabular} \\
\hline 8 & $65 \quad 697280$ \\
\hline 9 & $\begin{array}{lll}5 & 19 & 29 \\
\end{array}$ \\
\hline 10 & 316473 \\
\hline 11 & 21 \\
\hline 12 & 75 \\
\hline 13 & 32 \\
\hline
\end{tabular}

$\mathrm{Na}$ osnovu projektovanih ruta dobijaju se pokazatelji rada voznog parka, prikazani u tabeli 2.
- u razlicitim primerima $(80,100 \mathrm{i}$ 120 zahteva) predeni put sa putnicima je $50 \%$ do $51 \%$, a predeni put bez putnika $49 \%$ do $50 \%$ ukupnog predenog puta;

- ucešce predenog puta bez putnika je veliko, jer se svi zahtevi za prevoz realizuju na direktnim relacijama od izvora do cilja kretanja (kapacitet vozila je jedan putnik);

- vreme rada vozila obuhvata: vreme vožnji sa putnicima ( $26 \%$ do $32 \%$ ), vreme vožnji bez putnika ( $24 \%$ do $26 \%$ ) i vreme cekanja vozila ( $42 \%$ do $50 \%$ );

Pokazatelji rada voznog parka

Tabela 2

\begin{tabular}{|c|c|c|c|c|c|c|c|c|}
\hline Vozilo & $\begin{array}{c}\text { Broj } \\
\text { zahteva }\end{array}$ & $\begin{array}{c}\text { Ukupan } \\
\text { put } \\
(\mathrm{km})\end{array}$ & $\begin{array}{c}\text { „Pun } \\
\text { put“" } \\
(\%)\end{array}$ & $\begin{array}{c}\text { „Prazan } \\
\text { put“ } \\
(\%)\end{array}$ & $\begin{array}{c}\text { Ukupno } \\
\text { vreme } \\
(\mathrm{min})\end{array}$ & $\begin{array}{c}\text { „Pune } \\
\text { vožnje“ } \\
(\%)\end{array}$ & $\begin{array}{c}\text { „Prazne } \\
\text { vožnje“ } \\
(\%)\end{array}$ & $\begin{array}{c}\text { Vreme } \\
\text { cekanja } \\
(\%)\end{array}$ \\
\hline 1 & 16 & 207.74 & 55 & 45 & 472.47 & 36 & 29 & 35 \\
\hline 2 & 12 & 211.08 & 47 & 53 & 488.48 & 30 & 34 & 36 \\
\hline 3 & 10 & 122.77 & 64 & 36 & 437.93 & 26 & 15 & 59 \\
\hline 4 & 9 & 150.59 & 56 & 44 & 487.84 & 25 & 20 & 55 \\
\hline 5 & 8 & 179.74 & 50 & 50 & 388.24 & 34 & 34 & 32 \\
\hline 6 & 6 & 97.76 & 63 & 37 & 251.92 & 36 & 21 & 43 \\
\hline 7 & 6 & 100.83 & 48 & 52 & 256.23 & 28 & 30 & 42 \\
\hline 8 & 4 & 74.73 & 48 & 52 & 208.74 & 25 & 27 & 48 \\
\hline 9 & 3 & 67.34 & 50 & 50 & 357.18 & 14 & 14 & 72 \\
\hline 10 & 3 & 59.62 & 51 & 49 & 488.75 & 9 & 8 & 83 \\
\hline 11 & 1 & 24.00 & 33 & 67 & 36.00 & 34 & 66 & 0 \\
\hline 12 & 1 & 14.00 & 50 & 50 & 21.00 & 50 & 50 & 0 \\
\hline 13 & 1 & 27.54 & 33 & 67 & 41.30 & 33 & 67 & 0 \\
\hline
\end{tabular}

Analiza dobijenih pokazatelja za primere sa 80,100 i 120 zahteva za prevoz ukazuje na sle dece [10]:

- primenom razvije nog he uristic kog algoritma dobija se skup ruta vozila, koji obezbeduje realizaciju svih evidentiranih zahteva za prevoz;

- dobije ne rute vozila su najbolje sa aspekta definisane funkcije cilja: minimizacija trajanja praznih vožnji i cekanja vozila, uz poštovanje svih prisutnih ogranicenja;
- zahtevi za prevoz realizuju se u momentima koje zadaju korisnici, tako da ne postoji kašnje nje zahteva vec cekanje vozila na pocetak realizacije zahteva. Cekanje je zastuplje no u svim primerima sa ucešcem od $42 \%$ do $50 \%$.

Razvijeni he uristicki algoritam i softverski paket obezbeduju primenu u konkretnim uslovima. Dobije ni skup ruta je najbolji sa aspekta definisane funkcije cilja. Nedostatak razvijenog algoritma su ogranicene dimenzije problema koji se rešava (najviše 125 zahteva za prevoz). 


\section{Zakljucak}

U radu je opisan he uristic ki algoritam za projektovanje ruta vozila u transportnom sistemu „Nazovi vožnju“ (Dial-a-Ride), koji ima veliku primenu u praksi. U razvije nim ze mlja ma Evrope i Amerike postoje prevoznici koji prevoze razlicite kategorije putnika po principima Dial-a-Ride. Prevoz robe i putnika u razlicitim poslovnim sistemima pripada ovoj grupi prevoza.

Opisani he uristicki algoritam se, u jednom koraku, zasniva na me todi dinamic ko programiranje, što, sa jedne strane, doprinosi kvalitetu dobijenih rešenja. Realizovanja te stiranja na velikom broju primera ukazuju na dobijanje kva litetnih rešenja u konkretnoj primeni. Sa druge strane, osnovni nedostatak razvijenog at goritma jesu ogranicene dimenzije proble ma, koji se rešava, što je upravo posle dica primene optimizacione metode. Ovako definisan he uristicki algoritam predstavlja dobru osnovu za razvoj sistema za podršku odlucivanju, jer dozvoljava da dispeceri koriguju dobijena rešenja, kao i za projektovanje ruta vozila kroz više iteracija. Uz dodatne modifikacije (kapacitet vozila $>1$, postojanje vremenskih intervala, dodatna ogranicenja $u$ sistemu, i dr.) predloženi algoritam se može primeniti i za rešavanje slic nih klasa ruting-proble ma.

Literatura:

[1] Bodin, L.; Golden, B.: Classification in vehicle routing and scheduling, Networks, 11, 97-108 (1981).

[2] Desrosiers, J.; Dumas, Y.; Soumis, F.: A Dynamic Program ming Solution of the Large-Scale Single-Vehicle Diala-ri de Problem with Time Windows, The American Journal of Mathematical and Management Science, 6, 301-325 (1986).

[3] Laporte, G.; Louveaux, F.: Mercure, H., The Vehicle routing Problem with Stochastic Travel Times, Transportation Science, 26, 161-170 (1992).

[4] Lenstra, J.; Rinnooy kan, A.: Complexity of vehicle routing and scheduling problems, Networks, 11, 221-227 (1981).

[5] Magnanti, T.: Combinatorial Optimization and Vehicle Fleet Planning: Perspectives and Prospects, Net works, 11, 179-214 (1981).

[6] Muller-Merbach, H.: Heuristic Procedures for solving Combinatorial Optimization Problems in Transportation, Transportation Research, 8, 377-378 (1976).

[7] Psaraftis, H.: A dynamic program ming solution to the single vehicle many-to-many immediate request dial-a-ri de problem, Transportation Science, 2, 130-154 (1980).

[8] Psaraftis, H.: Scheduling Large-Scale Advance-request Dial-a-ride Systems, American Journal of Mthematical and Management Science, 6, 327-367 (1986).

[9] Radivojevic, G.: Multidisci plinarni pristup optimizaciji upravljanja autobuskim voznim parkovima, Centar za multidisciplinarne studije, Magistarski rad, Beograd (1992).

[10] Radivojevic, G.: Fazi sistemi za projektovanje ruta saobracaj nih sredstava, Saobracajni fakultet, Doktorska di sertacija, Beograd (2002). 